\title{
The role of computer tomography in the surgical management of cystic lesions.
}

Astrid B. M. Riikenhuizen, Gerald B. van den Top und Anton J. van den Belt*,

Department of Equine Sciences and Division of Diagnostic Imaging*, Utrecht University,

\begin{abstract}
Summary
One of the treatment options for subchondral bone cysts is surgical debridement. The approach (intra-articular or transcortical) depends on the location, appearance, size and stage of the lesion, as well as the surgeon's preference. Diagnosis is based on clinical examination, diagnostic analgesia and diagnostic imaging. For bone cysts plain radiography is the examination of choice because of its high diagnostic capabilities. However, sometimes it is hard to determine the exact localisation as well as the existence of a connection with the joint. In two patients a cystic lesion could be diagnosed on the dorsopalmar radiographic view. To determine the exact anatomical location, necessary to plan the surgical approach, computed tomography (CT) was performed. The value of the CT scan in both patients for providing a definitive location of the lesions proved indispensable. It permitted appropriate decision-making regarding surgical treatment and planning of the surgical approach. By knowing the exact anatomical localisation it was feasible to recognise during surgery the minimal cartilage changes as a sign of an underlying cystic lesion (case 1) or visualise the cartilage lesion by selective resecting the overlying hypertrophied synoviale membrane (case 2).
\end{abstract}

Keywords: Equine, subchondral bone cysts, cystic lesion, computer tomography

\section{Die Rolle der Computer-Tomographie in der chirurgische Behandlung der subchondraler Zyste}

Die Therapie der Wahl bei zystischer subchondraler Knochenläsionen ist das chirurgische Debridement. Der Zugang ist dabei abhängig von Lokalisation, Form und Größe der Läsion sowie von der Übung und Vorliebe des Chirurgen intraartikulär oder transkortikal. Die Diagnose wird aufgrund des klinischen Befunds, der diagnostischen Anästhesien und des Röntgenbildes gestellt. Normalerweise kann die Läsion durch konventionelle Radiographie lokalisiert werden, aber oft sind die Zysten nur im dorsopalmaren Strahlengang sichtbar. Röntgenaufnahmen sind in der Regel Summationsaufnahmen. Mit Aufnahmen in verschiedenen Ebenen versucht man, den zystischen Defekt besser lokalisieren zu können, aber die so gewonnene Information ist trotzdem nicht immer ausreichend. Mit der Computer-Tomographie (CT) lässt sich eine überlagerungsfreie Darstellung von Knochenteilen erreichen und sie kann zudem die genave anatomische Lokalisation der Knochenzyste und deren Verbindung zur Gelenk darstellen. Am Beispiel zweier Patienten wird die Rolle der CT zur exakten Lokalisation einer zystischen Knochenläsion und zur Planung des geeigenten chirurgischen Zugangs deutlich.

Schlüsselwörter: Pferd, subchondraler Knochenzyste, Computer-Tomographie

\section{Introduction}

One of the treatment options for subchondral bone cysts is surgical debridement. The approach (intra-articular or transcortical) depends on the location, appearance, size and stage of the lesion, as well as the surgeon's preference (Kold and Hickman 1984, Hickman and Ellis 1984, Nixon 1990, Howard et al. 1995, Hogan et al. 1997, Fürst et al. 1997, Jackson et al. 2000, Heidbrink and Sader 2002, Bodo et al. 2004, Story and Bramlage 2004). Diagnosis is based on clinical examination, diagnostic analgesia and diagnostic imaging. For bone cysts plain radiography is the examination of choice because of its high diagnostic capabilities. However, sometimes it is hard to determine the exact localisation as well as the existence of a connection with the joint. Conventional radiographs depict a three dimensional object as a two dimensional image. Computed tomography (CT) overcomes this problem by scanning thin slices of (a part of) the body with a narrow x-ray beam which rotates around the (part of the) body, producing an image of each slice as a cross section of the body (part) and showing each of the tissues in a variable slice diameter (range $1-10 \mathrm{~mm}$ ).

In this article 2 cases are described in which the additional help of the CT as a diagnostic tool was indicated to exactly locate the subchondral bone cyst and determine the extension and the communication with the joint in order to decide whether an intra-articular or extra-articular approach should be used.

\section{Case studies}

Case 1

A 7 year old Dutch Warmblood gelding was referred to the department of equine sciences for evaluation of a right hind 
limb lameness and backproblem. The horse had been lame for about 3 months with a gradual onset and had been treated twice for back problems by a manual therapist. On examination, the lameness was assessed as grade 3 out of 5 . Examination of the hind limbs and pelvic region was unremarkable. Flexion of the metatarsophalangeal joint of the right hind limb exacerbated lameness by 2 grades whereas the flexion test of the contralateral limb was negative. After a low six-point anaesthesia lameness disappeared.

Radiographic examination (lateromedial (LM), dorso $45^{\circ}$ medial-plantarolateral oblique (D45M-PILO), dorso $45^{\circ}$ lateral-plantaromedial oblique (D45L-PIMO) and dorso-plantar (DPI) view, without grid) of the metatarsophalangeal joint revealed mild signs of arthrosis at the dorsoproximal margins of the first phalanx and sesamoid bones quality grade 2 out of 5 on both limbs (Smallwood et al. 1985, Dik 1992). Intraarticular anaesthesia of the metatarsophalangeal joint the following day resolved the lameness. Additional radiographic examination (dorsoplantar-DPI, with grid) of the metatarsophalangeal joint demonstrated the presence of a cystic lesion ( 4 by $4 \mathrm{~mm}$ ) in the region of the disto-abaxial part of the

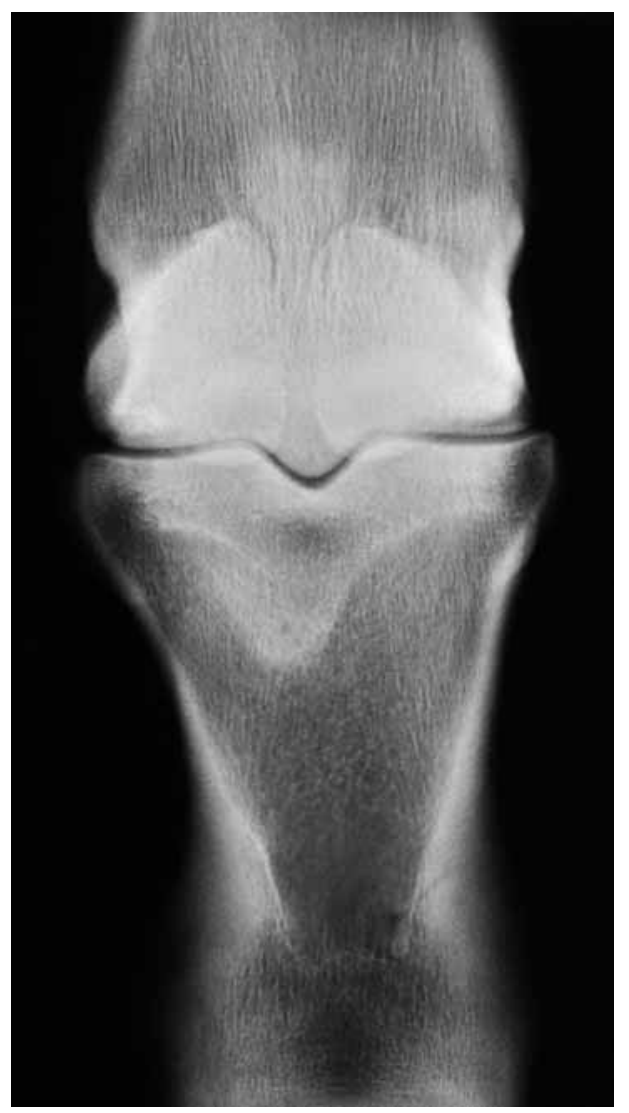

Fig 1 The dorsoplantar - DPI (with grid) radiographic view of the metatarsophalangeal joint with the cystic lesion (rectangular area) of the first patient.

Dorsopalmare Aufnahme mit Raster des Fesselgelenks mit Gelenkszyste (Patient 1).

medial condyle of the metatarsal bone or proximal phalanx (Fig 1). Surgical management was advised, however an exact localisation of the lesion was necessary to plan the surgical approach and CT-scan was advised.

The horse underwent CT-imaging of the affected joint while under general anaesthesia. Two $\mathrm{mm}$ thick slices were obtai- ned using a CT-scanner (Philips CT Secura, Single Slice Spiral Scan) with settings of $120 \mathrm{kV}, 120 \mathrm{~mA}, 0.70 \mathrm{sec}$.. On the transverse sections of the CT-scan an interruption in the plantar cortex of the lateral part of the plantar eminence of the first phalanx was visible, which continued as a cystic lesion with surrounding sclerosis just distal to the joint where the distal sesamoid ligaments attach (Fig 2). The connection of the lesions with the joint became clear as well as the exact localisation.

Based on these findings an arthroscopic approach was chosen immediately following the CT imaging. Prior to surgery Ampicillin (5 gr intravenously, Ampi dry $5000^{\circledR}$ Dopharma, Zalmweg 24, 4941 VX Raamsdonkveer, the Netherlands) was administered. The horse was positioned in lateral recumbency with the affected limb uppermost, with the arthroscopic portal in the proximal part of the plantar pouch of the metatarso-phalangeal joint and the instrument portal $2 \mathrm{~cm}$ distal to the arthroscopic portal just proximal to the collateral ligament. During surgery the metatarsophalangeal joint was flexed as much as possible. A mild synovitis was observed with an increase in the number of synovial villi varying in thickness

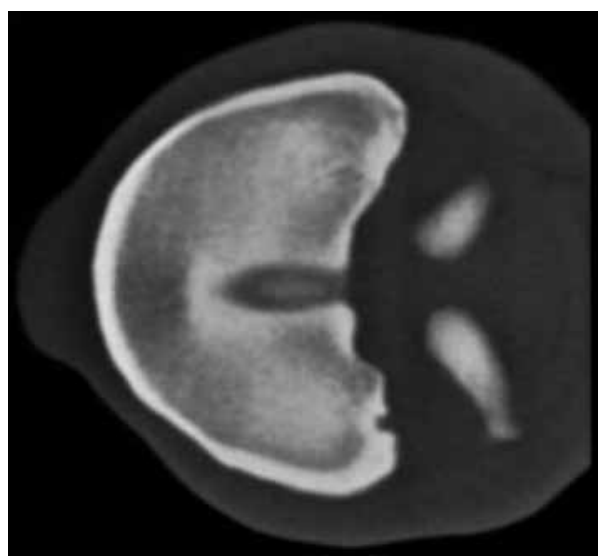

Fig 2 Transverse CT image of the cystic lesion (rectangular area) in the first phalanx of the first patient.

Transversales CT-Bild der Gelenkszyste im Fesselbein (Patient 1).

Mild arthrotic findings were present, including ecchondrosis at the edges of the joint and both apices of the sesamoid bones and focal thinning of the cartilage of the medial condyle. No cartilage changes were noticed on the first phalanx.

Based on the CT-scan the location of the cystic lesion was estimated and synovial villi were resected using a motorized synovial membrane resector (Linvatec shaver, full radius resectorblade 4,2 mm Linvatec Deutschland, Frankfurter Str. 74 - D64521 Groß-Gerau). Subsequently, a small indentation became visible and with a burr (spherical burr $3,5 \mathrm{~mm}$ ) the surrounding cartilage was removed and the underlying cyst (size $4 \mathrm{~mm}$ by $4 \mathrm{~mm}$ ) was debrided. The joint was flushed with saline $(0,9 \%)$ and the skin was closed with interrupted sutures (Monocryl ${ }^{\circledR}$ 2-0 Poliglecaprone 25). A bandage was applied for 7 days. The recovery was uneventful. Wound healing occurred by primary intention. Because of the synovitis noticed intraoperatively Triamcinolon-acetonide (8 mg Kenacort-A10 ${ }^{\circledR}$ Bristol-Meyers Squibb BV ,Vijzelmolenlaan, 3447 GX Woerden, the Netherlands) was instilled into the joint 7 days after surgery. The owner was advised to boxrest the horse for 3 weeks with daily hand walking, followed by pasture exercise. 
After 2 months the cystic lesion was no longer visible on radiographs (dorsoplantar-DPI, with grid). The lameness had improved to 2 out of 5 , and a slight effusion of the metatarso-phalangeal joint was present. The owner was advised to start training after another 4 weeks pasture turnout. Four months after surgery no lameness was present at the right hind limb, unfortunately the horse had a lameness of his left forelimb with secondary back problems due to soreness of the latissimus dorsi muscles.

\section{Case 2}

A 9 year old Haflinger gelding was acute and progressively lame since 2 weeks. At admission the pony showed a supporting limb lameness of his right forelimb (4 out of 5). Clinical examination revealed a distended metacarpophalangeal joint and flexor tendon sheath on his right fore limb. The flexion test of the distal extremity exacerbated the lameness (1 grade) whereas the carpal flexion test and the flexion test of the left fore limb were negative. After epineural block, the low 4 point anaesthesia resolved the lameness. Radiographs of

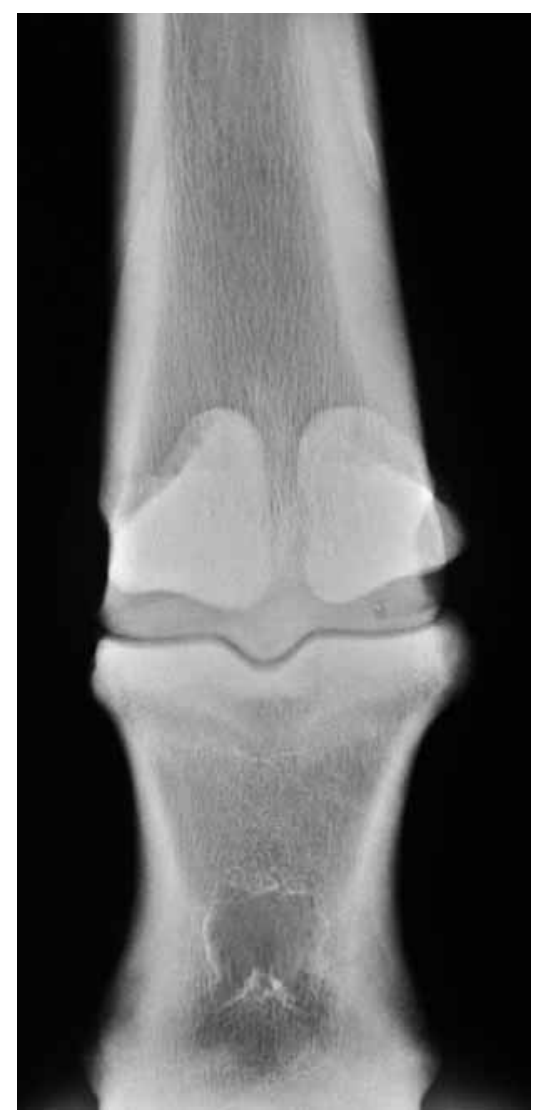

Fig 3 The metacarpal bone on the dorsopalmar view (with grid) of the cystic lesion (rectangular area) of the second patient.

Dorsopalmare Aufnahme mit Raster des Röhrbeins mit Gelenkszyste (Patient 2).

the distal extremity ( $L M$, dorso $45^{\circ}$ medial-palmarolateral oblique (D45M-PaLO), dorso $45^{\circ}$ lateral-palmaromedial oblique (D45L-PaMO) and dorsopalmar (DPa)), revealed mild arthrosis (joint margins classification 2 out of 5 and sesamoid bones classification of 2 out of 5). A small cystic lesion was noticed medial in the medial condyle of the metacarpal bone on the dorsopalmar view (with grid) (Fig 3). To determine the exact localisation and the feasibility of arthroscopic access to the lesion a CT scan was made with the pony under general anaesthesia. The CT scan demonstrated the lesion with a sclerotic zone in the dorsomedial aspect of the metacarpal bone with a connection with the joint (Fig 4).

Fig 4 CT image of the cystic lesion in the metacarpal bone (rectangular area) of the second patient.

CT-Aufnahme der Gelenkszyste im Röhrbein von Patient 2.

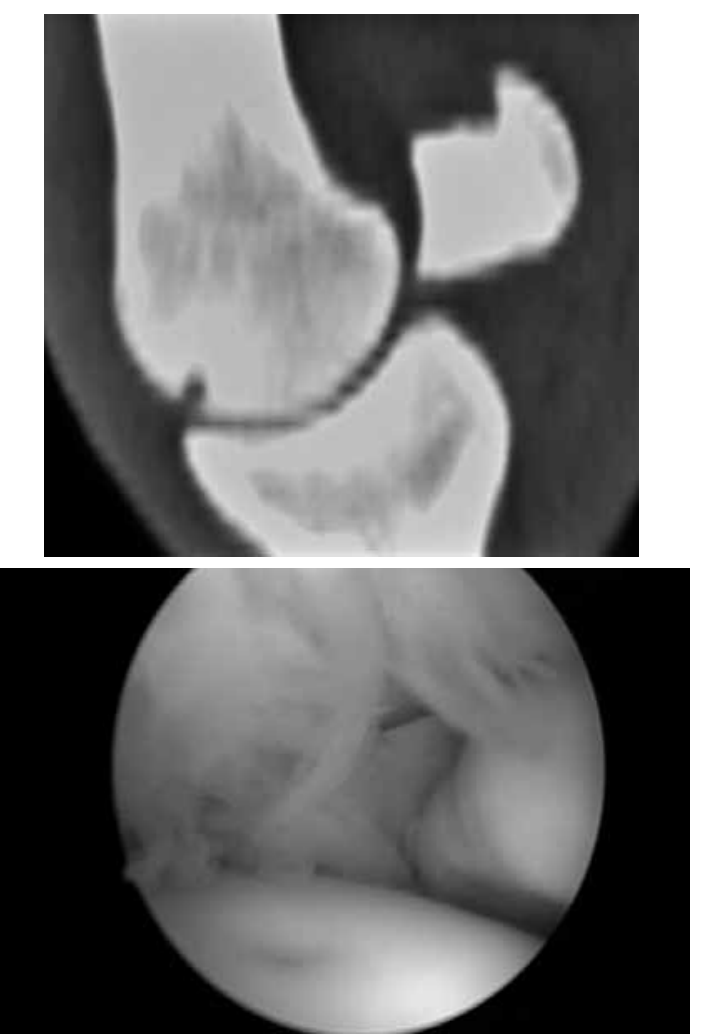

Fig 5 Arthroscopic view on the indentation in the cartilage of the metacarpal bone of the second patient. Arthroskopische Ansicht der Einbuchung des Gelenkknorpels am Röhrbein distal (Patient 2)

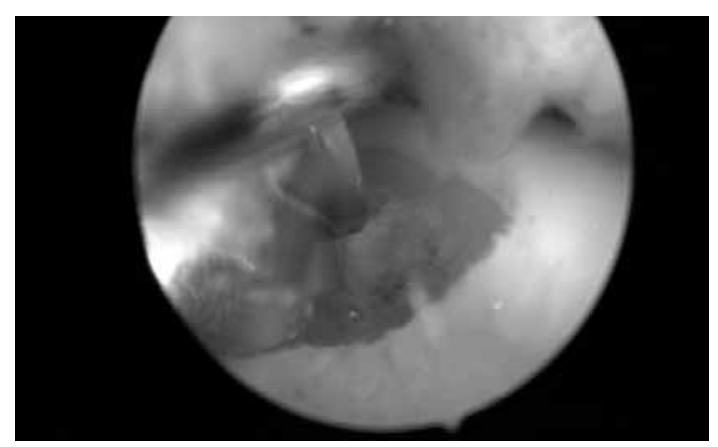

Fig 6 Arthroscopic view after partial debridement. The cystic lesion is filled with fibrous tissue.

Arthroskopische Ans9icht nach partiellem Debridement. Die Zyste ist mit Bindegewebe gefüllt.

From the images obtained it was clear that an arthroscopic approach was possible and the pony was taken to the operation theatre. Prior to surgery the pony was positioned in lateral recumbency. The arthroscopic portal was located dorsolaterally in the dorsal pouch and the instrument portal dorsomedially. During surgery a mild synovitis was observed. While flexing the joint a small "pin head" indentation became visible at $1 / 3$ of the width of the condyle (Fig 5). The cartila- 
ge of the medial condyle revealed no changes, whereas the lateral condyle showed various longitudinal striae. (The cartilage of the sesamoid bones was unchanged with some ecchondrosis at both apices. With a motorized synovial membrane resector hypertrophied synovial villi, which diminished the view of the lesion, were removed. The cystic lesion, containing clear fluid and fibrotic tissue, was debrided with a $3,5 \mathrm{~mm}$ spherical burr (Fig 6). The joint was flushed with saline. The skin incisions were sutured (simple interrupted sutures Monocry $\left.{ }^{\circledR} 2-0\right)$ and a bandage was applied for 7 days. The wound healed by first intention and 7 days post-operatively the joint was treated intra-articularly with dexamethasone (8 mg Dexadreson ${ }^{\circledR}$, Intervet Nederland, Kleine Broekweg 1, 5831 AP, Boxmeer, the Netherlands).

The pony was discharged and the owner adviced to provide 3 weeks stall rest followed by hand walking on an even surface. Two months later the lameness had diminished to 2 out of 5 and radiographic examination revealed a clearly visible cyst. An additional period of controlled exercise on an even surface was advised. After another 2 months the pony was sound and radiographically the lining of the lesion had become vague and bony ingrowth was detectable, mild periarticular osteophyte formation was noted. The owner was advised to increase training.

\section{Discussion}

Computer tomography (Greek tome=a cutting, graphia from graphein = to write) is often not necessary for the evaluation of bone cysts because of the accurate diagnosis obtained by radiography.

For bone cysts plain radiography remains the examination of choice because of its high diagnostic capabilities. However, cysts are known to become visible radiographically only when at least $30 \%$ of the bone mineral content has been absorbed. If visible, small cystic lesions can be consistently recognised on a dorsopalmar view, but not always on additional views due to summation of opacities of superimposed contours (Barbee et al. 1987, van Suntum and Hartung 1989, Fürst et al. 1997). Therefore, it is not always possible to localise the lesion exactly, which is necessary in order to decide whether an intra-articular or a transcortical approach is most appropriate. This lack of sensitivity does not apply to CT whereby multiple images of a specific area are obtained from different angles, resulting in an increased level of detail as well as a 3dimensional representation, allowing recognition and characterization of a specific lesion (Garcia-Lopez and KirkerHead 2004). A CT scan makes it possible to determine the precise localisation and extension of the cyst as well as to detect communication with the joint. This technique has also been found to be valuable in humans for confirming the diagnosis of subchondral lytic lesions, to assess the need for surgery and to plan the surgical approach (Zinman et al 1982).

Disadvantages of the use of the CT scan include false positive diagnoses of cystic lesions mentioned in human literature (de Wilde et al. 2004), the necessity for general anaesthesia and the expense for the owner. However, CT does not require much time and images can be interpreted fairly quickly, allowing immediate subsequent surgical management.
Obtaining additional radiographic views at slightly different angles will provide extra information, but poses a radiation hazard to personnel, is time consuming and involves the risk that the location of the cyst might still remain unclear (Hanson et al. 2004).

Magnetic resonance imaging (MRI) might also have been an option for these cases, but communication with the joint through the articular cartilage can be difficult to detect because of the interslice gap used in most MRI sequences (Zubrod et al. 2004). Furthermore MRI increases duration of the procedure, which increases the risk for the patient when imaging is subsequently followed by surgery. Because of the nature and the complexity of the imaging system and intrinsic maintenance costs, MRI is unavoidably a more expensive procedure than $\mathrm{CT}$.

In both patients the cystic lesion could only be detected on the dorsopalmar/plantar radiographic view and could have been located more dorsal or palmar. Whether an articular (dorsal or palmar/plantar) or transcortical approach was necessary could not be determined based on the radiographic findings. Fluoroscopy as an image guiding technique during surgery was not feasible due to the same reasons as why the cysts could not be visualised by plain radiography.

The value of the CT scan in both patients for providing a definitive location of the lesions proved indispensable. It permitted appropriate decision-making on how to approach the lesion. The presence of an articular communication and consequently articular defects supported the decision to opt for of surgical treatment. By knowing the exact anatomical localisation it was feasible to recognise during surgery the minimal cartilage changes as a sign of an underlying cystic lesion (case 1) or visualise the cartilage lesion by selective resecting the overlying hypertrophied synoviale membrane (case 2).

\section{Literature}

Barbee D. D., Allen J. R., Grant B. D., Riggs M. W., Crawley G. R. and Sande R. D. (1987): Detection by computed tomography of occult osteochondral defects in the fetlock of a horse. Equine Vet J 19, 556-568.

Bodo G., Hangody L., Modis L. and Hurtig M. (2004): Autologous osteochondral grafting (mosaic arthroplasty) for treatment of subchondral cystic lesions in the equine stifle and fetlock joints. Vet Surg. 33, 588-596.

De Wilde V., De Maeseneer M., Lenchik L., Van Roy P., Beeckman P. and Osteaux M. (2004): Normal osseous variants presenting as cystic or lucent areas on radiography and CT imaging: a pictorial overview.Eur J Radiol. 51, 77-84

Dik K. J. (1992): De Veterinaire Keuring Van Het Paard (ed. Wagenaar, G.). 2nd edn. Bunge, Utrecht.

Fürst A. , Kaegi B., von Rechenberg B. and Auer J. A. (1997): Die Behandlung von 5 Pferden mit subchondralen zystoiden Defekten im Fesselbein, Pferdeheilkunde 13, 147-161

Garcia-Lopez J. M. and Kirker-Head C. A. (2004): Occult subchondral osseous cyst-like lesions of the equine tarsocrural joint. Vet Surg. 33, 557-64

Jackson W. A., Stick J. A., Arnoczky S. P. and Nickels F. A. (2000): The effect of compacted cancellous bone grafting on the healing of subchondral bone defects of the medial femoral condyle in horses. Vet Surg 29, 816 
Hickman J., Kold S. and Ellis D. (1984): Use of bone cement in two equine orthopaedic cases. Equine Vet J 16, 543-545

Hogan P. M., Mcllwraith C. W., Honnas C. M., Watkins J. P. and Bramlage L. R. (1997): Surgical treatment of subchondral cystic lesions of the equine third metacarpal bone: results in 15 horses (1986-1994). Equine Vet J 6, 477-482

Hanson J. A., Seeherman H. J., Kirker-Head C. A. and O'Callaghan M. W. (1996): The role of computed tomography in evaluation of subchon dral osseous lesions in seven horses with chronic synovitis. Equine Vet J 28, 480488

Heidbrink U. H. and Sader R. (2001): Surgical therapy of bone cysts with osteoconductive and osteoinductive bone substitutes. Veterinary Surgery 30, 300

Howard R. D., Mcllwraith C. W. and Trotter G. W. (1995): Arthroscopic surgery for subchondral cystic lesions of the medial femoral condyle in horses: 41 cases (1988-1991). J Am Vet Med Assoc 206, 842-850

Kold S. E. and Hickman J. (1984): Results of treatment of subchondral bone cysts in the medial condyl of the equine femur with an autogenous cancellous bone graft. Equine Vet J 16, 414-418

Nixon A. J. (1990): Osteochondrosis and osteochondritis dissecans of the equine fetlock. Compend Contin Educ Pract Vet.12,14631475

Smallwood J. E., Shively M. J., Rendano V. T. and Habel R. E. (1985): Projections according: A standardized nomenclature for radiographic projections used in veterinary medicine. Veterinary Radiology, $26,2-9$
Story M. R. and Bramlage L. R. (2004): Arthroscopic debridement of subchondral bone cysts in the distal phalanx of 11 horses (1994-2000). Equine vet. J. 36, 356-360

Suntum van M. and Hartung K. (1989): The appearance of subchondral cystoid defects in the joints of the distal extremities of the horse. Tierarztl Prax. 17, 79-83

Zinman C. and Reis N. D. (1982): Osteochondritis dissecans of the talus: use of the high resolution computed tomography scanner.Acta Orthop Scand.53, 697-700

Astrid B. M. Rijkenhuizen DVM PhD Dipl ECVS,

Department of Equine Sciences,

Faculty of Veterinary Medicine,

Utrecht University,

Yalelaan 12,

3584 CM Utrecht

The Netherlands

a.riikenhuizen@vet.uu.n

\section{Kompetenz und Sicherheit bei der Kaufuntersuchung}

\section{Pferdeheilkunde}

\section{Vertrag über die}

Untersuchung eines Pferdes 